\title{
Article
}

\section{BIM Role within the Conceptual Design Phase: A Case Study of a UK Construction Project}

Gerges, Michael, Mayouf, Mohammad, Watson, Paul David Julian, John, Godfaurd Adjaie, Ahmed, Ehab Kamel and Wenman, Brandon Available at http://clok.uclan.ac.uk/29091/

Gerges, Michael ORCID: 0000-0001-5986-7301, Mayouf, Mohammad, Watson, Paul David Julian ORCID: 0000-0002-7414-4061, John, Godfaurd Adjaie ORCID: 0000-0002-5016-5909, Ahmed, Ehab Kamel ORCID: 0000-0002-6737-9356 and Wenman, Brandon (2019) BIM Role within the Conceptual Design Phase: A Case Study of a UK Construction Project. International Journal of Architecture, Engineering and Construction, 8 (1). pp. 54-62. ISSN 1911-110X

It is advisable to refer to the publisher's version if you intend to cite from the work. http://dx.doi.org/10.7492/IJAEC.2019.006

For more information about UCLan's research in this area go to

http://www.uclan.ac.uk/researchgroups/ and search for < name of research Group>.

For information about Research generally at UCLan please go to http://www.uclan.ac.uk/research/

All outputs in CLoK are protected by Intellectual Property Rights law, including Copyright law. Copyright, IPR and Moral Rights for the works on this site are retained by the individual authors and/or other copyright owners. Terms and conditions for use of this material are defined in the policies page. 


\title{
BIM Role within the Conceptual Design Phase: A Case Study of a UK Construction Project
}

\author{
Michael Gerges ${ }^{1, *}$, Mohammad Mayouf ${ }^{2}$, Paul Watson ${ }^{1}$, Godfaurd John ${ }^{1}$, Ehab Kamel Ahmed ${ }^{1}$ \\ Omar Selim ${ }^{3}$ and Brandon Wenman ${ }^{4}$ \\ ${ }^{1}$ School of Engineering, University of Central Lancashire, Preston, United Kingdom \\ ${ }^{2}$ School of Engineering and Built Environment, Birmingham City University, Birmingham, United Kingdom \\ ${ }^{3}$ BIMarabia, Cairo, Egypt \\ ${ }^{4}$ Department of Engineering, University of Lancaster, Lancaster, United Kingdom
}

\begin{abstract}
The application of building information modelling (BIM) during the construction cycle of any development varies. Systematically, the way BIM's applied during the initial phase will have a direct influence on phases that follow afterwards. Previous research focused on the application of BIM and concentrated on various aspects, which included sustainability or how to overcome the loss of data/information. However, it limited its focus on the application during a specific phase of the project. Analysis outlined both the benefits a nd barriers of a pplying B IM d uring the c onceptual d esign $\mathrm{p}$ hase. T he study suggests that an informed evaluation of the application of BIM during any particular phase should take in consideration different stakeholders' roles and responsibilities.
\end{abstract}

Keywords: Building information modelling (BIM), conceptual design, stakeholder engagement, construction industry

DOI: http://dx.doi.org/10.7492/IJAEC.2019.006

\section{INTRODUCTION}

The design phase of a construction project is where stakeholders' needs and requirements are identified to develop drawings, which could include either a 2D or 3D model, specifications, drainage plans and building regulation drawings (Newton 1995; Gray and Hughes 2001). The designs will enable the various stakeholders to visualize the way the building aesthetics, but more importantly identify the critical aspects with relation to the building/project.

Kochan (1991) opines that, within the design phase of a project is when all issues and defects should be identified and resolved. In addition, Freire and Alarcon (2000) identified that, within the design phase, issues can be resolved with minimal impact, which in turn becomes more cost effective. Therefore, the design phase of a project is critical to ensure that all parties understand their roles and responsibilities, and that the project can run smoothly where an acceptable success can be achieved at the end project. Kochan (1991) suggests that poor designs will result in issues arising throughout the project, which may include, delays and disruption to the construction programme, re-work, an unhappy client, and communication breakdown. Furthermore, the cost implication of issues not being addressed within the design phase and arising with the construction phase can drastically increase, due to, need for new materials, wastage and re-work, leading to Freire and Alarcon (2000) suggestion that all parties included throughout the whole of the project should have input within the design phase.

It is generally acknowledged that professional, parties have different skills, knowledge and expertise, and therefore including all parties within the design phase will result in any issues being identified earlier. It is suggested that a design phase of a project can outline up to $67 \%$ of the final projects timespan, however this is due to quality and functionality being designed within the build, the client's needs being obtained and the build meeting all legislative constraints (Freire and Alarcon 2000; Kochan 1991). Contrary to this, it helps to reduce the physical construction time, reducing defects and issues arising throughout the projects as suggested by Newton (1995) and Gray and Hughes (2001), state that "a design stage of what take time is a detailed design phase". Therefore, this is the reason for why all parties should be involved within the design process, each party, as stated earlier, will have different knowledge and expertise and therefore give a different insight into the elements involved within project and the issues of which could arise, as published by Newton (1995) and Gray and Hughes (2001). This as El-Diraby et al. (2017) advo-

*Corresponding author. Email: mgerges1@uclan.ac.uk 
cates embraces the need for collaborative design. (Gomes et al. 2016) concurs and further states that a design should be one that can engage not only the professionals, but also non-expert and the end-users of the project. Cidik et al. (2014) suggests that BIM (Building Information Modelling) is an evaluation tool, which provides a platform to evaluate the different options when producing a conceptual design. Further suggesting that BIM offers the designers the ability to assess the different design alternatives at the conceptual stage of a project (Jalaei and Jrade 2015), thus allowing all the stakeholders views and contributions to be included within the design.

\section{LITERATURE REVIEW}

\subsection{Design Process: General View}

The design phase of a construction project involves finding methods of problem solving, as suggested by Pressman (1993) and Lawson (1997). Kochan (1991) agrees and further proposes that within the design phase of a project, the stakeholder's needs and requirements are to be identified. Following this, the various professionals can develop a concept incorporating the clients' ideas within drawings and develop these into a number of models, which in turn can be presented as a visual product to the stakeholders to see the concept design. As previously discussed, these can include, site drawings, a 2D or 3D model, specifications, drainage plans, building regulation drawings, or any products, which will help ensure all the client's needs are included.

Kochan (1991) proposes that the design phase of a project is when any issues or defects should be identified and resolved by either designing them out by implementing design changes, or material/quality amendments. Freire and Alarcon (2000) identified that within the design phase, issues can be resolved with minimal cost effects upon that project, due to re-designs and alterations being made. Therefore, the design phase of a project is critical to ensure the project can run smoothly and ensure project success can be achieved through to the end of the project. Kochan (1991) further suggests that bad design will mean that issues will arise throughout the project and its construction phase, these issues that occur, could cause delays, re-working and costing issues. Furthermore, the cost implication of issues arising within the construction phase can drastically increase, due to, new materials needed, wastage or design changes, which mean rework is required. Kochan (1991) further proposes and suggests that a good design phase is critical; the research also put forward, states that a good design phase of a project can outline up to $70 \%$ of the final projects timespan. This is predominately due to quality and functionality designed within the build, the client's needs being designed within the build, and the build having to meet all legislative constraints. On the other hand, this helps to reduce the physical construction time, as well as defects and issues arising throughout the projects. Therefore, this is one of the reasons why all stakeholders should be involved within the design process, as each stakeholder will have different knowledge, experience and therefore give a different insight into elements involved within project, as publish by Newton (1995) and Gray and Hughes (2001). Thus, having identified how traditional design processes can affect a project, the next section of the literature review will identify drawing methods and how they have developed over time.

\subsection{Design Planning}

Austin et al. (1999) postulates that a design program is required to be both accessible and workable, as in doing this it will help to achieve a more organized and efficient project, therefore project success will be easier to obtain. Cole (1993) suggests that a design program is usually set to meet a detailed deadline, which is set by either the client or main contractor before any work commences. The program should also include information on how the set deadline can be achieved. Information such as timings for information to be released to contractors, the procurement method and contractual proceeding, release of funds, set review meeting and lastly the design development and schedule. Austin et al. (1999) insinuated that, within the construction industry, there is a growing acknowledgement for design planning, especially within the areas of, design solutions and information scheduling.

\subsection{Design Management}

It is claimed that design management and project management are heavily linked (Newton 1995; Gray and Hughes 2001). However, design management is set around managing the design, therefore must deliver a set design, on time and meeting the previously set stakeholders needs, requirement(s) and finally their budget. A competent professional within this sector (design manager), usually carries out this role for the design management of a project. However, within some cases, a team of personnel who work within the design phase carry out this role, but it is predominately dependable upon the project size and complexity. Furthermore, it is also suggested that while there can be a team of whose role it is to carry out the design management, there is a need for a single point of responsibility. This helps to control the creation of design and people know the point on contact should an issue occur. The role of a designer is to co-ordinate, control and monitor all the design activities, whilst also interacting with other parties (e.g. client, project manager, contractor) to ensure all needs and requirements are being met throughout the design and that the client is satisfied with the end result.

\subsubsection{Design Management: Problems and Issues}

Developments have been made within the design phase and how it is managed; however, there are still few examples of total project success, as suggested by Gray and Hughes (2001). The current procedures and methods used to date within the design phase still are full of issues, such as, poor communication, lack of adequate or missing documents, lack of coordination between parties, incorrect information being transferred and parties working from different revisions (Goedert and Meadati 2008). The current approach used to help manage the design process therefore is usually inappropriate and inadequate. Supported by the research conducted by Karhu and Lahdenpera (1999), who opined that the process is generally shapeless harnessing, poor communication and lack of trained personnel, which leads to insufficient understanding of the design process. 


\subsubsection{Design Management: Design Changes}

Within the construction industry, especially during the design phase of the project, one of the principal issues and causes for delay is design changes. When a design change is made, it means that re-working is required, irrespective of which stage the projct is at, as suggested by Morris et al. (1999) however the impact and cost for the design change can drastically impact upon how far the project has gone. Machowski and Dale (1995) suggest, that design changes can account for up to $58 \%$ of a designers' worked hours within a project and can be accountable for up to $89 \%$ of re-work throughout a project. In addition, Koskela (1992) states that some of the design changes made within projects have a large administrative cost and can cost upon $49 \%$ of the overall cost for the design phase of the project, and even well-managed projects can have an average cost between 5 and $15 \%$.

\subsubsection{Design Management: Integration}

A construction project, irrespective of its size or scale, involves the engagement of several parties and professionals who have different skills, knowledge and interests, so that they all work together in order for the project to be a success (Mitropoulos and Tatum 2000). Ensuring that this completed and that all parties involved within the project are working together is vital (Kagioglou et al. 1998; Mitropoulos and Tatum 2000). Therefore, the Integration of the design and construction can be difficult, ensuring communication between parties is obtained, organisation is kept and that planning is updated regularly is crucial, as a more detailed design will be achieved. Information gathered from the different parties all of whom, have different skills and expertise, will help to prevent issues arising, this is observed by Mitropoulos and Tatum (2000) who stated that "as the constructive parties will have an input into the design and all necessary development to be carried out this will ensure that suitable design has been done and solutions are in place for any issues of which were not designed out of the project". Furthermore, Mitropoulos and Tatum (2000) opines that the principle outcome of a project is to achieve client satisfaction. Therefore, it is clear that the design has to meet client's needs and, in turn, the integration of design and construction, which has to be carried out, as Egan (1998) postulated, is a fundamental weakness within the industry, as a client can change their needs throughout a project. Egan (1998) proposed that improvement within quality and efficiency throughout the UK construction industry is required. The design phase was a major factor; this is why the identification of the process BIM was critical to the construction industry. BIM is a tool, which helps to improve both coordination and commutation between all who are involved within the project. Moreover, BIM is also a tool, which produces a model and is built up from intelligent building components. The model created is a representation of the proposed finished project as recommended by Goedert and Meadati (2008). Therefore, BIM can be used as a tool to show the clients a representation of the proposed finished project before the "live" work commences.

\subsection{Building Information Modelling (BIM): An Overview}

There is a plethora of definitions of BIM. Karhu and Lahdenpera (1999) define BIM as "a modelling process that contains building information and components". Contrary to this definition, Autodesk suggest that, "BIM is an integrated process for exploring a project's key physical and functional characteristics digitally before it is built". Integrating these definitions $\mathrm{BIM}$ is a modelling system, which creates a $3 \mathrm{D}$ object that is created from the building information components, and is carried out to meet client specifications and needs. Furthermore, as Sackey et al. (2014), suggest BIM can be described as a socio technical system due to its technical dimensions, its ability to produce a $3 \mathrm{D}$ model and its aptitude to allow any scheme to be re-engineered.

BIM as previously suggested is a tool, which creates a 3D object that is created from building information components, and is carried out to meet client specifications and needs. BIM models are created within conceptual phase and used throughout the design and construction phases as pointed out by Mitropoulos and Tatum (2000). Within the conceptual phase, a designer creates a parametric 3D model, which represents the finished build. This model, once created, can generate all the traditional drawing required, such as plans, elevations, sections, floor plans and schedules with notes being linkable to each. Furthermore, as proposed by Karhu and Lahdenpera (1999), when a client makes a design change the designer only needs to change the original drawing and the other drawings will change automatically. Lastly, a BIM model can be compressed and transferred into several file formats, which can then be shared amongst all parties of the AEC teams (Sabol 2008).

\subsection{BIM: Implementation and Application}

Liu et al. (2016) propose that albeit BIM has led to changes in the way that designers and contractors work, it seems that organisations and specifically the role of the designer and construction teams often do not significantly change. BIM is known throughout the construction industry for its ability to improve communication between all parties involved in a project, by the use of a centralized model. It is also suggested that the centralized model helps reduce the level of separation work carried out by everyone working upon the same project model (Hardin 2009). However, this could cause issues as different members of the AEC team may obtain different levels of BIM capabilities. Furthermore, Eisenmann and Park (2012) found within their research that the parties' knowledge level within BIM was very important to achieve the most benefits from BIM and therefore, recommend that team 'experts' are allocated within each projects design phase. Moreover, Eastman et al. (2011) says that, "within highly specialized works, skills are required that may be relatively unique within the industry".

BIM as a tool have several advantages, which can drastically impact upon the conceptual phase, if not limited by the user. Some of the advantages of BIM are that BIM helps to speed up the design and construction process. BIM also helps with conflict resolution, as it aids to identify conflict early within the development meaning that any needed modification can 
be made as put forward by Bryde et al. (2013). Furthermore, the single entry and transporting files, previously discussed within the study are key advantages. Bryde et al. (2013) also points out within their study that BIM also provides details on how each of the building components are assembled correctly. Therefore, helping to cut down on physical construction time as well as rework. Finally, one of the biggest advantages from a client point of view, is that BIM allows operational simulation. According to Bryde et al. (2013), "BIM allows clients to have a real time viewing of the proposed project by an animated model showing a client a walk through".

\subsection{BIM: Barriers and Issues}

Although BIM is seen to be the future, there are still a few issues, which need to be addressed before the full benefits can be reaped by the industry. There are three main issues with BIM, expertise, cost and workflow (Sabol 2008). Bryde et al. (2013) suggested that workflow is not an issue when implementing BIM, but the there are some major players that influence BIM implementation such as expertise and cost. Lack of expertise of BIM is a barrier, as suggested by Bryde et al. (2013) as there are not many experts out there, due to the fact that BIM requires extensive training. Another factor suggested by Bryde et al. (2013), is that BIM is a new technology tool and therefore difficult to get a grasp of. Cost is a major issue as there is a high initial upfront cost, which is also suggested by Sabol (2008) and Sebastian (2011), this includes the hardware, software, training and implementation. Therefore, as suggested by Bryde et al. (2013), this supposed cost is the main reason why companies don't make the transaction to BIM, as there is a risk of spending money before actually saving, so it is a gamble. Further to the two disadvantages previously stated, other studies have shown that human error and communication are also major issues when using BIM, however this is not due to the software but the users.

The main feature that makes BIM possible is its "interoperability", of which means its capability to coordinate and interact as a constant representation of the same building throughout a project and within all the AEC member's hands. According to Howell and Batcheler (2012), the success of BIM depends upon the sharing of information among the various BIM models. This is a key feature within BIM as stated earlier within this study. However, Howell and Batcheler (2012) further suggest that numerous software's require different ways in which BIM can be used within them. In addition, Moon et al. (2011) argued, "eight in ten BIM users say there is a significant need to improve interoperability as different software packages from may not interact with each other correctly. Therefore, this will cause issues within communication and exchange of information, which in turn can affect a project drastically. On the other hand, it is not possible for one program to handle all functions needed to carry out a project, for example, create the drawing, specification, and write the program as well as schedule, whilst also doing the costing and creating a Gantt chart. Therefore, separate software's are necessary. This is the reason Industry Foundation Classes (IFCs) were developed by the International Alliance for Interoperability (IAI), which has set out and has introduced rules and protocols, to provide the constancy when it comes to the method in which the data is represented within the building model as defined and pointed out by Azhar et al. (2008) within his study.

\section{RESEARCH METHODOLOGY}

Bryman and Cramer (2011) propose that a mixed method approach can provide a more insightful, yet informative investigation for the phenomenon being investigated. Within a mixed method, approach data can be collected within a short period of time. Furthermore, Saunders et al (2007) points out that qualitative approaches are best suited to analyze content that is non-numerical in nature. For this study, data was attained using mixed methods through conducting questionnaire surveys and semi-structured interviews. Therefore, this paper aims to gather quantitative data for the advantages and disadvantages of BIM within the conceptual phase, and qualitative data for the impact on interoperability and degree of implementation. The research commenced using secondary data obtained from literature to identify related studies within relation to application of BIM within the conceptual design phase. A questionnaire was constructed based upon what pervious researchers found to be the advantages and barriers of implementing BIM this was then distributed to construction experts to complete, they were asked to rate their level of agreement upon statement from previous studies, the answers were from strongly agrees to strongly disagree. The semi-structured interviews aimed to ask about the challenges involved with interoperability, as well as the advantages and barriers of BIM being implemented with the conceptual phase.

\subsection{Questionnaire Survey}

The questionnaire aims to determine what construction experts thought the main disadvantage and advantages of BIM are. These questionnaires were sent out to construction personnel, who operate within the conceptual phase of a project or have an expert insight within BIM. The questionnaire was designed with predominately rating scale questions, respondents were asked to state their opinion or preference for a particular question on a scale from strongly agrees to strongly disagree. Within data collection there are numerous ways of which a questionnaire can be sent, for example, email, post, over a telephone or face to face as suggested by Naoum (2007). The questionnaire was divided mainly into two parts:

(1) Part 1: considers background information about the respondents such as years of experience, type of current employer, and the sector type that they are employed in.

(2) Part 2: the main focus of these questions was to determine what construction experts thought the main disadvantage and advantages of BIM are.

It is important to indicate that the last questions of the questionnaire had open-ended questions and were implemented for the respondents to leave any further information which they thought was applicable to further the study and could aid to reach the aim/objective of the study.

\subsection{Interviews}

Semi-structured interviews were selected with each participant invited to take part in a 20-30minutes interview, held at the 
participants' offices. Using this method of data collection allows the researcher to modify the questions within the interview, based upon the interviewees' reply. Furthermore, it also aids in determining the interoperability issues of BIM implementation and arrives at identifying the impact of the system when implemented within the conceptual phase of a construction project which is the principle aim of the research study. This interview method was chosen over unstructured or structured interviews, because this study intends to answer the research questions by asking specific questions, without missing any important information. By using a semi-structured method of interview the researcher can modify the questions within the interview based upon the interviewees' replies and experiences, whilst still having set targets to be met through the key questions.

\section{RESULTS AND ANALYSIS}

This section respectively discusses the key results and analysis of the data obtained using questionnaires and interviews. It is important to indicate that both the questionnaire survey and interviews have explored BIM advantages and barriers; hence, the results obtained from both are integrated into a separate section.

\subsection{Questionnaires}

\subsubsection{Respondents' Background}

The researcher chose these questions to open the questionnaire, as it provides an overview of the respondents' years of experience, area of experiences and knowledge of BIM, which in turn will outline the person, and their knowledge in completing the questionnaire.

\subsubsection{Respondents' Years of Experience}

The first question establishes the respondents' years of experience. The respondents were asked to mark the suitable choice that indicates their years of experience within the construction projects.

The researcher received 56 respondents as indicated within Figure 1, however only (39.28\%) have had more than 10 years' experience. Majority of respondents of who had less than 10 years of experience which represent $(58.93 \%)$ of the total respondents. In a way this indicates that the questionnaire has been filled by younger, although comparatively inexperienced professionals. The positive side to this is that the younger generation may be more aware and knowledgeable about new ICT tools and technologies such as BIM, compared to the others who have been in the industry for a longer time.

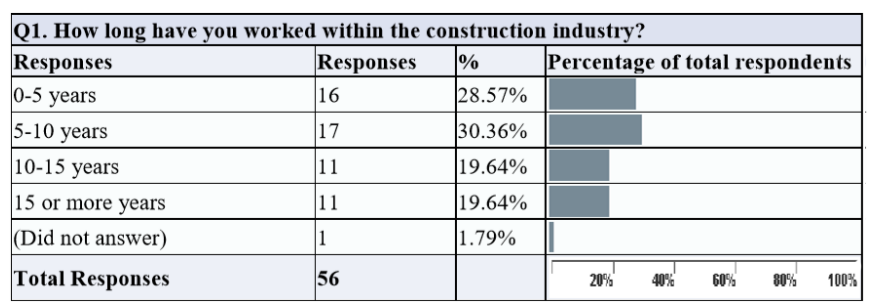

Figure 1. Respondents' years of experience.

\subsubsection{Age of the Company}

Figure 2 shows the number of years the respondents' worked for company, has been operating within the construction industry. It is observed that a majority of the respondents' companies had been operating within construction sector for 15 or more years with $(71.43 \%)$ stating this. In addition, the data also shows that very few respondents were from companies, which had less than 5 years' experience within the construction industry (5.36\%). Therefore, these statistics indicate that the sample population obtained is employed within companies, which have operated within construction sector for a number of years and have greater chance of understanding the design and construction process as put forward by (Kochan 1991) who says that "with years comes experience."

\begin{tabular}{|c|c|c|c|}
\hline \multicolumn{4}{|c|}{ Q2. How long has your company been within construction industry? } \\
\hline Responses & Responses & $\%$ & Percentage of total respondents \\
\hline $0-5$ years & 3 & $5.36 \%$ & \\
\hline $5-10$ years & 7 & $12.50 \%$ & \\
\hline $10-15$ years & 5 & $8.93 \%$ & \\
\hline 15 or more years & 40 & $71.43 \%$ & \\
\hline (Did not answer) & 1 & $1.79 \%$ & \\
\hline Total Responses & 56 & & $20 \%$ \\
\hline
\end{tabular}

Figure 2. Companies years of experience.

\subsubsection{Companies' Construction Projects Expertise}

Figure 3 presents the result of question 3, which was, "what area of the construction industry does your company focus upon?". For this question, the respondents could provide answers for more than one option. It is observed that the majority of the respondents worked within companies, which are involved in construction of buildings $(80.36 \%)$ and $(30.36 \%)$ for transport. Very few respondents are from companies, which are involved within hydraulic structures sector (7.14\%). The above statistics indicate that respondents work in construction companies, which are involved in building, transport and infrastructure operations. Since the BIM tool is mainly related to buildings and construction design, the majority of the sample population work within these sections, therefore, using this research offers a great advantage as most of the respondents should have used the BIM tools personally or have a greater knowledge of it.

\begin{tabular}{|c|c|c|c|}
\hline \multicolumn{4}{|c|}{$\begin{array}{l}\text { Q3. What area of the construction industry does your company focus upon? (More than one option can } \\
\text { be answered) }\end{array}$} \\
\hline Responses & Responses & $\%$ & Percentage of total respondents \\
\hline $\begin{array}{l}\text { Buildings (Housing, hospitals, military facili- } \\
\text { ties, universities, government) }\end{array}$ & 45 & $80.36 \%$ & \\
\hline $\begin{array}{l}\text { Transport (Highway, tunnel, bridge, railway, } \\
\text { etc.) }\end{array}$ & 17 & $30.36 \%$ & \\
\hline $\begin{array}{l}\text { Hydraulic structures (Dams, irrigation sys- } \\
\text { tems.) }\end{array}$ & 4 & $7.14 \%$ & \\
\hline Other (Please specify) & 7 & $12.50 \%$ & \\
\hline (Did not answer) & 1 & $1.79 \%$ & \\
\hline Total Responses & 98 & & $20 \% \% \quad 40 \% \quad 60 \% \% \quad 80 \% \quad 100 \%$ \\
\hline
\end{tabular}

Figure 3. Companies expertise.

\subsection{Interviews}

This section of discusses the key result obtained in relation to the interviews and questions. In addition, this section will also analyse the data collected from secondary results and compare 
it to the new data collect, in doing this a depth of information will be obtain and similarities or difference will be identified.

\subsubsection{Common Errors within the Conceptual Phase}

When questioned about the common errors within the conceptual phase, both interviewees highlighted that some of the common errors that occur throughout the process, are clients having an unrealistic deadline to meet, or responsibilities and roles of parties not being known. Interviewee 1 made this clear within the answer given, "with regards to BIM implementation common errors which occur are, defining how information will be shared, and at what level of detail is required. These responsibilities and roles being defined and unrealistic timelines being set for the project." Furthermore, interviewee 2 identified that "Roles and responsibilities of parties have to been correctly outlined, and clients who set unworkable deadlines can cause major challenges". Kochan (1991) outlined that, roles and responsibilities of parties are heavily impact by the method of procurement chosen, therefore choosing the procurement early within the design phase can help all parties to determine their set roles and responsibilities. Kochan (1991) points out that roles and responsibilities should be included within the projects contract. Therefore, both parties know what is excepted from them throughout the project, Eastman et al. (2011) shared this view and suggest that the contract is a legal document, therefore should a party fail to meet the roles and responsibilities included within, the other party could claim for breach of contract.

\subsubsection{BIM and Information Leverage}

Within the interviews the researcher asked the question of advantages information leverage throughout a project. To this question both interviewees outlined that the biggest advantage was that BIM provides transferable files and that within using BIM 'one source of truth' can be identified as suggested by interviewee 1, who said "My personal opinion is that a common data environment (CDE) should be formed at the earliest stage possible so that there is only 'one source of truth/shared information' where all the relevant project information, by all relevant parties is shared and available here". Further to this interviewee 2 pointed out that "BIM helps us share information between parties, by program sharing and transferrable files". Further to this the researcher feels these views are supported within the literature, as this advantage of BIM was discussed. Karhu and Lahenpera (1999) indicated that program sharing and transferrable files are a major advantage throughout the project however within their study they discuss that issue within interoperability of BIM can cause challenges within program sharing and transferring files, therefore as addressed within (Kochan 1991) study communication within the AEC is vital and can make or break a project.

\subsubsection{BIM and Interoperability Issues}

When the interviewees were questioned about the challenges involved with interoperability between software's vendors, the most commonly identified challenge was the incapability to decide on communication roles. However, the respondents felt that the software vendors are taking lengths to address these issues, as observed from Interviewee 1, who said "ex- porting structural design into the model/ detailing software such as Revit can have many issues. Coordination of beams, nodes being incorrect, incorrect mapping of elements, etc." and "Generally, from a civil/structural consultant's perspective, IFC (Industry Foundation Class) has been quite a revelation with regards to interoperability between various parties on a project" Furthermore Interviewee 2 pointed out that "the biggest problem with interoperability being the hopelessness to agree on communication roles. However, majority of the software vendors have gone to great efforts to deal with interoperability issues." Therefore, in relation to the question the researcher feels this view is fully supported within the literature. Kochan's (1991) study found that interoperability issues are due to different software's entitling different details, therefore this issue would have to be addressed by the software vendors, which according to Goedert and Meadati (2008) is slowly being carried out. In addition, Eastman et al. (2011) identified that there are interoperability issues between different BIM software applications, but sees that if the interoperability issues of BIM were to be fully addressed then BIM could advance further within the construction industry and the AEC team would have a closer partnership.

\subsection{BIM Advantages and Barriers}

It is observed that different aspects including BIM's role in conflict resolution had a high response of strongly agree (58.93\%), help client to visualize the project (60.5\%) and reduction in overall cost (46.43\%). This indicates that the majority of respondents felt these attributes to be major advantages. However, the majority of respondents suggested BIM had a drastic impact on the actual design process (48.21\%) for strongly agree and $(35.71 \%)$ for agree. These views are supported and questioned in literature. However, Hallberg and Tarandi (2011) argued that BIM plays a limited role in the architectural design process, whereas, Succar (2008) found similar result to this study and had the view that BIM plays a vital role within design phase. Furthermore, the respondents were questioned upon role of BIM within the construction process $(32.14 \%)$, whereas electronically transferring file only had (7.14\%). Hallberg and Tarandi (2011) found only a small percentage saw this as an advantage (11.54\%). Furthermore, Succar (2008), results found operation simulations (Mean $=1.81$, $\mathrm{SD}=1.024)$. This study would suggest this is high obtaining a percentage of $(50 \%)$ for agree and $(37.50 \%)$ for strongly agree. Within the study conducted, Eastman et al. (2011), strongly identify the importance of BIM and its ability within easing construction field operations. The researchers current study mirrors this, obtaining the percentages of $(32.14 \%)$ for strongly agree and (44.64\%) for agree. Moreover, Boktor et al. (2013) identified that BIM plays a key role in simulation and visualization, which is also demonstrated within this study (50\% for agree and $37.50 \%$ for strongly agree). The difference in results of this study and others may be explained by the need for better awareness of BIM. As identified within the studies, there is a lack of trained personnel this is outlined within Baldwin et al. (1999) who shared the view that BIM is used more in boardrooms rather than in field operations.

It is observed that there are many perceived different disadvantages of BIM. These include the lack of trained person- 
nel, which obtained a percentage (33.93\%) for strongly agree and $(42.86 \%)$ for agree. This issue was mirrored with Howard and Bjork (2008) who obtained a $($ Mean $=4.0, \mathrm{SD}=1.130)$. In contrast, a study by Azhar (2011) presented that there is an increasing number of training manuals and experts to teach BIM. Moreover, a major issue highlighted within Pishdad and Beliveau (2010) study was, that personnel are reluctant to change from previous ways/methods, which was also rated highly within the current study having a percentage $(30.36 \%)$ for strongly agree and for agree a percentage of $(41.07 \%)$. Howard and Bjork (2008) identified within their study that personnel didn't think BIM is costly when setting out. However, within the current research, the researcher found it to be a major issue obtaining a percentage of (42.86\%) for agree, moreover, Howard and Bjork (2008), study was carried out within the middle east and therefore culture may pay a part into how BIM is used. With the present determination of the UK government, presenting BIM as an integral part of the construction sector, this disadvantage may be easily overcome in a few years and may be a good sector for later research.

When the interviewees were questioned about advantages and barriers of BIM the interviewers outlined that, visualization and coordination were the two main advantages, Interviewee 1 explained that the main advantage he felt when using BIM, was its visualization abilities, Interviewee 1 said " the biggest advantage I see of BIM is its Visualization, within conceptual images, models, and walk through, which can be seen at an early stage thanks to BIM, this provides the client with a better idea of the end product", however Interviewee 2 saw BIMs main advantage as coordination, which was seen it the statement "Early BIM adoption can enable better coordination between the design team, thus enhancing efficiencies through design." However, within the literature carried out at chapter 2 of this study the researcher identified both of these advantages. Kochan (1991) pointed out that BIM helps clients to visually see the end product before live work commence. Moreover Moon et al. (2011) suggested clients can visually see corrections and designers only have to make corrections or design change to the original drawing and the other drawings change automatically thanks to single entry within BIM. In addition, both interviewees highlighted that the main barrier of implementing BIM is, that BIM requires training and that people aren't willing to make the transaction to BIM as put forward within the following statements obtained Interviewee 1 "Unwillingness to change - Although in more recent times, BIM is becoming more like business as usual. However, the traditional culture of construction projects tends to not enable change in my opinion. It's the term 'if it's not broken, don't fix it'. However, things may not be broken, but they're very inefficient in our industry, thus do need fixing. Therefore, it has been common, and it still is at some companies, that people do not realize the benefits of BIM and will be reluctant to embrace it fully." As suggested by Kochan (1991), this can be predominately due to people needing to undertake further training, which they don't feel, is necessary. Furthermore, a study carried out by Eastman et al. (2011) suggested that factors such as, age could be a factor to the unwillingness to change, for example, an older professional who has learnt ritualistic techniques may not be as comfortable changing due to being stuck in old ways, contrary to a younger professional, who could see it as an opportunity to advance. Within the same context, a younger professional could also have a better understanding and knowledge of computer and technology than an older colleague, due to being brought up in a generation where technology is common place.

\section{CONCLUSION AND RECOMMENDATIONS}

This paper aimed to focus on the implementation of BIM within the conceptual phase in a construction. Literature indicated that the majority of research studies on BIM implementation have focused on improving certain aspects such as sustainability or improving practices such as overcoming data/information loss. Mixed methods approach using interviews and questionnaire surveys was used to investigate both common errors within the conceptual phase and BIM implementation-related issues within any phase in a construction project. The BIM implementation issues were interoperability between BIM-based software used by members of the AEC team, information leverage throughout a project, and highlighting BIM's advantages and barriers. Findings suggest that the common issues during the conceptual phase are related to procurement methods and managing to execute tasks within the specified time. As with relation to BIM implementation, interoperability and information leverage related issues lie within the preparation of a BIM federal model while minimizing data loss and ensuring an early coordination plan between different stakeholders. The main advantages of BIM during the conceptual phase is the early detection of errors through visualization of synced building systems and components, and reducing number of changes through effective coordination between the client and the designer. Although the study provided an insightful investigation over BIM implementation within the conceptual phase, further investigation using real life case study is required to determine the issues faced when implementing BIM during early phases in a construction project.

\section{REFERENCES}

Austin, S., Baldwin, A., Hammond, J., and Waskett, P. (1999). Application of the analytical design planning technique in the project process. Proceedings of the Conference on Concurrent Engineering in Construction, Espoo, Finland.

Azhar, S. (2011). Building Information Modelling (BIM): Trends, benefits, risks, and challenges for the AEC industry. Leadership and Management in Engineering, 11(3), 241252.

Azhar, S., Hein, M., and Sketo, B. (2008). Building Information Modelling (BIM): Benefits, risks and challenges. Proceedings of the 44th ASC National Conference, Auburn, United States.

Baldwin, A. N., Austin, S. A., Hassan, T. M., and Thorpe, A. (1999). Modelling information flow during the conceptual and schematic stages of building design. Construction Management and Economics, 17(2), 155-167. 
Boktor, J., Hanna, A., and Menassa, C. C. (2013). State of practice of Building Information Modeling (BIM) in the mechanical construction industry. Journal of Management in Engineering, 30(1), 78-85. Available at: $<$ https://ascelibrary.org/doi/full/10.1061/\%28ASCE\%29 CO.1943-7862.0000747> .

Bryde, D., Broquetas, M., and Volm, J. M. (2013). The project benefits of Building Information Modelling (BIM). International Journal of Project Management, 31(7), 971-980. Available at: <https://www.sciencedirect.com/science/article/pii/S0263 786312001779>.

Bryman, A., and Cramer, D. (2011). Quantitative Data Analysis with IBM SPSS Statistics 17, 18 and 19: A Guide for Social Scientists, Routledge, New York, United States.

Cidik, M. S., Boyd. D., and Thurairajah. N., (2014). Leveraging collaboration through the use of Building Information Modelling. 30th Annual ARCOM Conference, Portsmouth, United Kingdom. Available at: $<$ http://researchopen.lsbu.ac.uk/1453/> .

Cole, E. (1993). Planning Building Design Work, Spon, London, United Kingdom.

Eastman, C., Teicholz, P., Sacks, R., and Liston, K. (2011). BIM Handbook: A Guide to Building Information Modeling for Owners, Managers, Designers, Engineers and Contractors. John Wiley and Sons, Hoboken, United States.

Egan, J. (1998). Rethinking construction. Construction Task Force, London, United Kingdom.

El-Diraby, T., Krijnen. T., and Papagalis. M., (2017). BIM based collaborative design and sociotechnical analytics of green buildings. Automation in Construction, 82, 59-74. Available at: $<$ https://www.sciencedirect.com/science/article/pii/S0926 580517305095>.

Eisenmann, S., and Park, B. (2012). Building Information Modeling's impact on team performance. Proceedings of the 48th ASC Annual International Conference, Birmingham, United Kingdom. Available at: <http://ascpro0.ascweb.org/archives/cd/2012/paper/CP RT150002012.pdf $>$.

Freire, J., and Alarcon, L. F. (2000). Achieving a lean design process. Proceedings of Conference of the 8th International Conference for the Group for Lean Construction, Brighton, United Kingdom.

Goedert, J. D., and Meadati, P. (2008). Integrating construction process documentation into Building Information Modeling. Journal of Construction Engineering and Management, 134(7), 509-516. Available at: <https://ascelibrary.org/doi/full/10.1061/\%28ASCE\%290 733-9364\%282008\%29134\%3A7\%28509\%29> .

Gomes, D., Tzortzopoulos, P., and Kagioglou, M. (2016). Collaboration through shared under-standing in the early design stage. 24th Annual Conference of the International Group for Lean Construction, Boston, United States.Available at: <http://eprints.hud.ac.uk/id/eprint/29052/> .

Gray, C., and Hughes, W. (2001). Building Design Management. Butterworth-Heinemann, New York, USA.

Hallberg, D., and Tarandi, V. (2011). On the use of open BIM and $4 \mathrm{D}$ visualization in a predictive life cy- cle management system for construction works. Electronic Journal of Information Technology in Construction, 16, 445-466. Available at: <http://www.divaportal.org/smash/record.jsf?pid=diva2\%3A478341\&dswid $=8313>$.

Hardin, B. (2009). BIM and Construction Management: Proven Tools, Methods, and Workflows. Wiley Publishing Inc., Indianapolis, United States.

Howard, R., and Bjork, B. (2008). Building Information Modelling - Experts' views on standardization and industry deployment. Advanced Engineering Informatics, 22(2), 271280 .

Howell, I., and Batcheler, B. (2012). Building Information Modeling two years later - Huge potential, some success and several limitations. The Laiserin Letter, New York, United States. Available at: $<$ http://www.laiserin.com/features/bim/newforma_bim. pdf $>$.

Jalaei, F., and Jrade, A. (2015). Integrating Building Information Modeling (BIM) and LEED system at the conceptual design stage of sustainable buildings. Sustainable Cities and Society, 18, 95-107. Available at: <https://www.sciencedirect.com/science/article/pii/S2210 670715000748> .

Kagioglou, M., Cooper, R., Aouad, G., Hinks, J., Sexton, M., and Sheath, D. (1998). Generic design and construction process protocol: Final report. University of Salford, Salford, United Kingdom.

Karhu, V., and Lahdenpera, P. (1999). A formalized process model of current Finnish design and construction practice. The International Journal of Construction Information Technology, 7(1), 51-71.

Kochan, A. (1991). Boothroyd / Dewhirst - quantify your designs. Assembly Automation, 11(3), 12-14.

Koskela, L. (1999). Management of production in construction: A theoretical view. Proceedings of the 7th International Group for Lean Construction Conference, Berkeley, USA.

Lawson, B. (1997). How Designers Think, 3rd Edition. The Architectural Press Ltd, London, United Kingdom.

Liu, Y., Nederveen, S. V., and Hertough, M. (2016) Understanding effects of BIM on collaborative design and constreuction: An empirical study in China. International Journal of Project Management, 35(4), 686-698.

Machowski, F., and Dale, L. (1995). The application of quality costing to engineering changes. International Journal of Materials and Product Technology, 10(3), 378-388.

Mitropoulos, P., and Tatum, C. (2000). Forces driving adoption of new information technologies. Construction Management and Economics, 126(5), 340-348.

Moon, H. J., Choi, M. S., Kim, S. K., and Ryu, S. H. (2011). Case studies for the evaluation of interoperability between a BIM based architectural model and building performance analysis programs. Proceedings of 12th Conference of International Building Performance Simulation Association, Sydney, Australia.Available at: <http://ibpsa.org/proceedings/BS2011/P_1510.pdf > .

Morris, J., Rogerson, J., and Jared, G. (1999) A tool for modelling the briefing and design decision making processes in construction. Cranfield University, Cranfield, United King- 
dom.

Naoum, S. G. (2007). Dissertation Research and Writing for Construction Students. Butterworth-Heinemann, Oxford, United Kingdom.

Newton, A. J. (1995). The improved planning and management of multi-disciplinary building design. Ph.D. Thesis, Loughborough University, Leicestershire, United Kingdom.

Pishdad, P., and Beliveau, Y. (2010). Integrating multi-party contracting risk management (MPCRM) model with Building Information Modeling (BIM). 27th International Conference: Applications in IT in the AEC Industry, Rotterdam, Netherlands.

Pressman, A. (1993). Architecture 101: A Guide to the Design Studio. Wiley, New York, United States.

Sabol, L. (2008). Challenges in cost estimating with Building Information Modeling. IFMA's World Workplace 2008, Dallas, United States.

Sackey, E., Tuuli, M., and Dainty, A. (2014). Sociotechnical systems approach to BIM implementation in a multidisciplinary construction context. Journal of Manage- ment and Engineering, 31(1), A4014005. Available at: <https://ascelibrary.org/doi/full/10.1061/\%28ASCE\%29 ME.1943-5479.0000303> .

Saunders, M. N., Lewis, P., and Thornhill, A. (2009). Research Methods for Business. Pearson Education Limited, Essex, United Kingdom.

Sebastian, R. (2010). Integrated design and engineering using Building Information Modelling: A pilot project of small-scale housing development in the Netherlands. Architectural Engineering and Design Management, 6(2), 103-110. Available at: <https://www.tandfonline.com/doi/abs/10.3763/aedm.201 $0.0116>$.

Succar B. (2008). Building Information Modelling framework: A research and delivery foundation for industry stakeholders. Automation in Construction, 18(3), 357-375. Available at: $<$ https://www.sciencedirect.com/science/article/pii/S0926 $580508001568>$. 